\title{
THE ENDOCRINOLOGY OF THE POST-PARTUM SOW
}

\author{
S. EDWARDS \\ Department of Physiology and Environmental Studies, University of \\ Nottingham, UK†
}

\begin{abstract}
A discussion on the reproductive physiology of the post-partum sow in the context of a symposium on the Control of Pig Reproduction must include a survey of the management practices currently in use during pregnancy and lactation and a consideration of the current state of knowledge relating to the endocrine events associated with lactation. The post-partum rebreeding of sows is one of the few areas of pig production which is still open to significant improvement in that losses in productivity still occur consistently at this time. However, it is not the purpose of this chapter to review the changing management practices being adopted, but more to summarize the endocrine status of the sow after parturition and through weaning to the first post-weaning oestrus.

In general there is a change in hypothalamic, pituitary and ovarian activity during pregnancy, induced by progesterone, which leads to the observed failure of ovulation in the pig and other species. If lactation does not occur, i.e. the offspring are weaned at birth or shortly afterwards, there is an interval post-partum during which reproductive cycles and ovulation are still suppressed. The suppression of reproductive activity in the absence of suckling and lactation can only be associated with a post-partum block on ovulation. In a majority of situations, however, this post-partum block on reproductive activity is complicated by the influence of suckling and lactation (Lamming, 1978). Reproduction post-partum is therefore dependent upon, and intimately concerned with, the complex interrelationships of the endocrine events controlling lactation. It is, therefore, relevant to examine the development of the axis controlling gonadotrophin secretion and to determine the stages of lactation at which its functional components become operational and also to propose ideas which may account for the lack of operational competence prior to this time.
\end{abstract}

\section{The endocrinology of the sow during lactation}

Since the two major groups of ovarian steroids, the progestagens and the oestrogens, are both capable of reducing the pituitary secretion of gonadotrophic hormones they may, by such means, directly suppress the †Present address: An Foras Taluntais, Grange Research Station, Dunsany, Co. Meath, Ireland. 
occurrence of oestrus and ovulation post-partum. However, a consideration of the literature available indicates that the corpora lutea of pregnancy are in a state of regression shortly before parturition, and for the first 2-3 days of lactation are represented by inactive corpora albicantia (Warnick, Casida and Grummer, 1950; Burger, 1952; Palmer, Teague and Venzke, $1965 \mathrm{a}, \mathrm{b})$. Associated with these morphological changes, the plasma levels of progesterone decrease sharply around the time of parturition and remain low throughout lactation (Ash and Heap, 1975; Baldwin and Stabenfeldt, 1975; Parvizi et al., 1976).

The demise of the corpora lutea at farrowing is associated with an increase in both the plasma (Sasser et al., 1973; Ash et al., 1973; Robertson and King, 1974; Ash and Heap, 1975) and urinary (Raeside, 1963) concentrations of oestrogens, which then fall rapidly after parturition and remain low throughout lactation (Ash et al., 1972; 1973; Edqvist, Einarsson and Settergren, 1974; Ash and Heap, 1975; Stevenson, Cox and Britt, 1981) as illustrated in Figure 21.1. Therefore, a block on pituitary

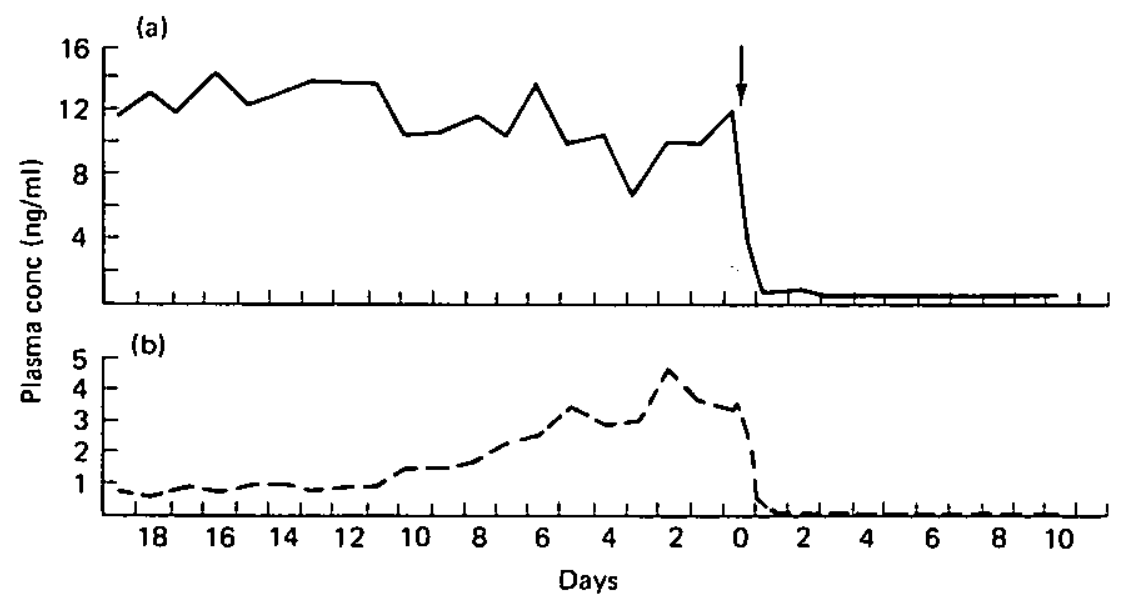

Figure 21.1 Plasma concentrations of (a) progesterone and (b) total unconjugated oestrogens in a sow during late pregnancy, parturition and early lactation. Day 0 and the arrow denote the day of parturition. From Ash and Heap (1975)

gonadotrophin secretion induced by ovarian steroids would not appear to account for the lack of ovulation seen in the lactating sow.

It has commonly been observed that a proportion of sows show behavioural oestrus at or just after farrowing (Warnick, Casida and Grummer, 1950; Burger, 1952; Baker et al., 1953; Self and Grummer, 1958) and whilst the proportion of sows showing this farrowing oestrus varies, it can be as high as $100 \%$. Since no surge of luteinizing hormone (Parvizi et al., 1976) or ovulation (Burger, 1952 and others) occurs at this oestrus the overt signs of heat have been attributed to the high levels of oestrogens seen at parturition, since no subsequent rise in oestrogens occurred in sows showing such an oestrus (Holness and Hunter, 1975). Hence lactation in the sow would appear to be associated with a period of ovarian follicular quiescence resulting in anoestrus and anovulation. Studies on the morphology of the sow ovary during lactation have 
indicated that follicle size and number decreases significantly during the first week of lactation but thereafter increases steadily (Palmer, Teague and Venzke, 1965a,b). Information from this and other laboratories has indicated that these follicles may reach a size capable of oestrogen secretion by 21-35 days post-partum. However, oestrus and ovulation do not normally occur until after weaning (Edqvist, Einarrson and Settergren, 1974; Edwards, 1980).

The two gonadotrophic hormones secreted by the anterior pituitary, follicle stimulating hormone (FSH) and luteinizing hormone (LH), are themselves under hypothalamic control via the releasing factor(s) gonadotrophin-releasing hormone(s) $(\mathrm{GnRH})$. The difficulties in assaying protein hormones, coupled with the technical difficulties in using the pig as an experimental animal, has meant that little data has been available until recently relating to the synthesis and release of gonadotrophins during lactation. This information is critical to our understanding of the factors controlling lactational anoestrus, since data previously discussed suggest that a lack of gonadotrophic stimulation may account for the depressed follicular activity associated with lactation.

The earliest data available on pituitary FSH and LH concentrations indicate that pituitary FSH is high, with little evidence of change throughout lactation (Lauderdale et al., 1965; Melampy et al., 1966; Crighton and Lamming, 1969). In contrast there is a sharp drop in pituitary LH activity between the end of pregnancy and day 14 of lactation (Melampy et al., 1966) which is maintained even after longer periods of lactation up to 56 days (Crighton, 1967). These data were interpreted by Crighton and Lamming (1969) as evidence for a lactation and/or suckling induced block on FSH release (but not synthesis), causing a lack of follicular growth and an inhibition of LH synthesis (and consequently release). However, a re-examination of the information on follicular development post-partum suggests that the pituitary secretions gradually escape from the inhibitory effects of suckling and lactation as follicular size and number increase gradually after the first 7-10 days of lactation (Palmer, Teague and Venzke, 1965a,b). Aherne et al. (1976) have reported levels of FSH in the plasma of lactating sows at three weeks post-partum which were similar to those observed by Rayford et al. (1974) in cyclic sows and gilts. Furthermore FSH levels appear to increase as lactation progresses particularly during the latter stages of a five-week lactation (Edwards, 1980; Stevenson, Cox and Britt, 1981) as illustrated in Figure 21.2. Whether this elevated secretion of FSH serves any physiological function is unclear at present, but it appears to reflect the aforementioned changes in ovarian follicular development seen as lactation progresses. The factors controlling FSH secretion during lactation are still undetermined but appear to involve an ovarian secretion (probably non-steroidal) which inhibits FSH release early in lactation (Stevenson, Cox and Britt, 1981; see Figure 21.2). This factor is probably folliculostatin, the putative inhibitor of FSH production (Campbell and Schwarz, 1979). As lactation progresses the secretion of this substance may serve only to limit excess, but not apparently normal, FSH secretion.

LH secretion during lactation is low (Parvizi et al., 1976; Stevenson, Cox and Britt, 1981), reflecting the low pituitary content of LH after the first 
(a)

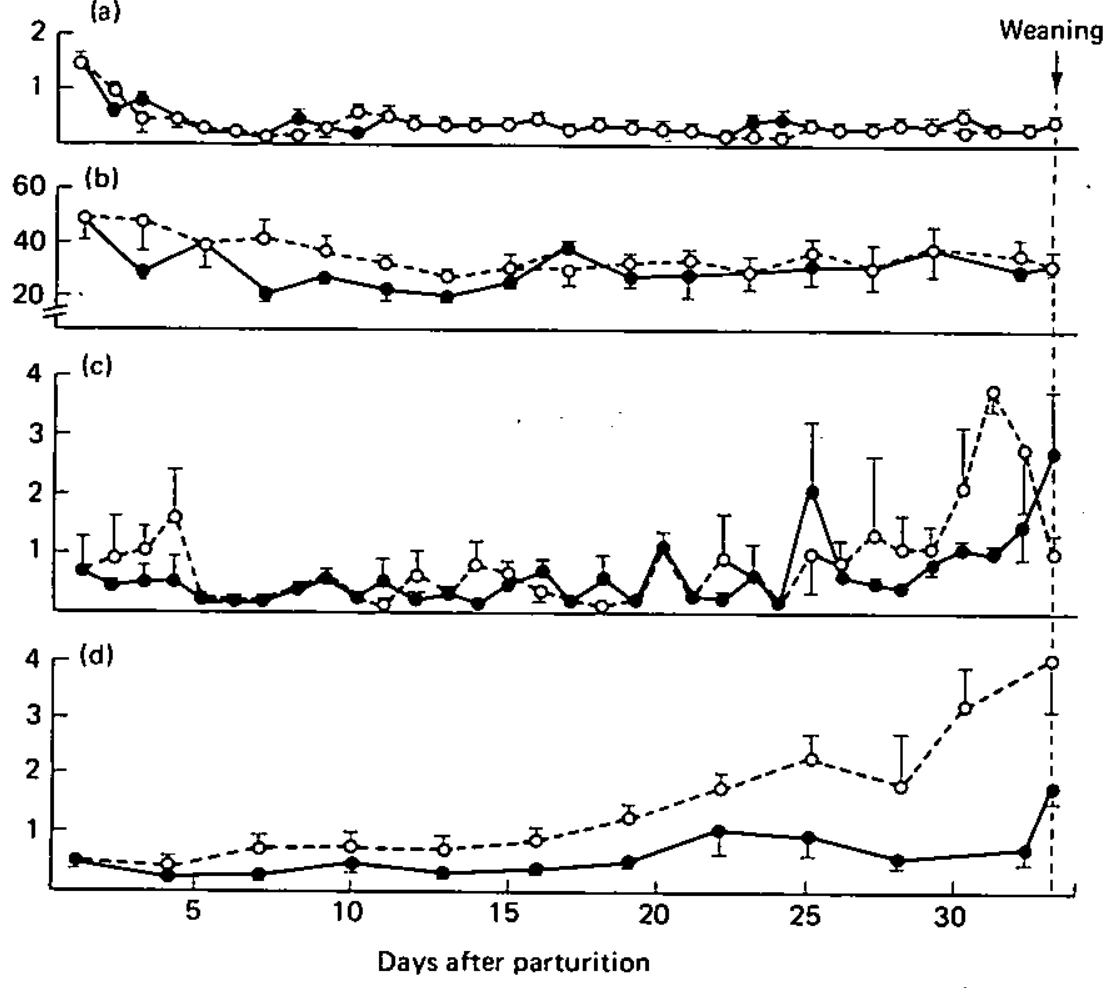

Figure 21.2 Serum concentrations of (a) progesterone $(\mathrm{ng} / \mathrm{ml}),(b)$ total oestrogens $(\mathrm{pg} / \mathrm{ml})$, (c) $\mathrm{LH}(\mathrm{ng} / \mathrm{ml})$ and (d) $\mathrm{FSH}(\mathrm{ng} / \mathrm{ml})$ during lactation in sows ovariectomized $(\mathrm{O} \ldots-\mathrm{O}) 2-4$ days after parturition or left intact (-O). Note that FSH concentrations are consistently higher after ovariectomy whereas LH concentrations are not different. By courtesy of Stevenson, Cox and Britt (1981)

week of lactation (Figure 21.2), but equivocal data exist as to whether basal LH secretion during the latter stages of lactation in particular differs from that seen throughout the oestrous cycle. Whereas Booman and van de Wiel (1980) report that basal LH is suppressed, others (Parvizi et al., 1976; Edwards, 1980) have shown that basal LH secretion is not significantly depressed during lactation. In comparison, Stevenson and Britt (1981) report that whilst LH secretion is suppressed early in lactation (day 7) it gradually increases during late lactation (21 days). A detailed study of the mechanisms controlling LH secretion is required before such equivocal data can be resolved, but work to date has indicated that, unlike FSH, ovarian secretions play no part in any inhibition of LH release which may occur during lactation (Figure 21.2) (Crighton and Lamming; 1969; Parvizi et al., 1976; Stevenson, Cox and Britt, 1981). Suckling may, however, directly suppress the release of LH releasing hormone, since hypothalamic stores of $\mathrm{GnRH}$ are lower at weaning in the pig than at any time during the weaning to oestrus interval (Cox and Britt, 1981) and by such means maintain depressed basal LH secretion during lactation as has been postulated in the rat (Minaguchi and Meites, 1967). 
A hormone classically associated with lactation and more recently with reproduction, is prolactin. Since analytical methods have become available to study the patterns of prolactin secretion in vivo its role in controlling lactational anoestrus in several species, including the pig, has been re-assessed. Nursing sows produce high levels of prolactin which decline gradually as lactation progresses, but are still 20-40 times basal levels at five weeks post-partum (van Landeghem and van de Wiel, 1978; Bevers, Willemse and Kruip, 1978; Stevenson, Cox and Britt, 1981) as illustrated in Figure 21.3. The ability of prolactin to block the stimulatory effects of the

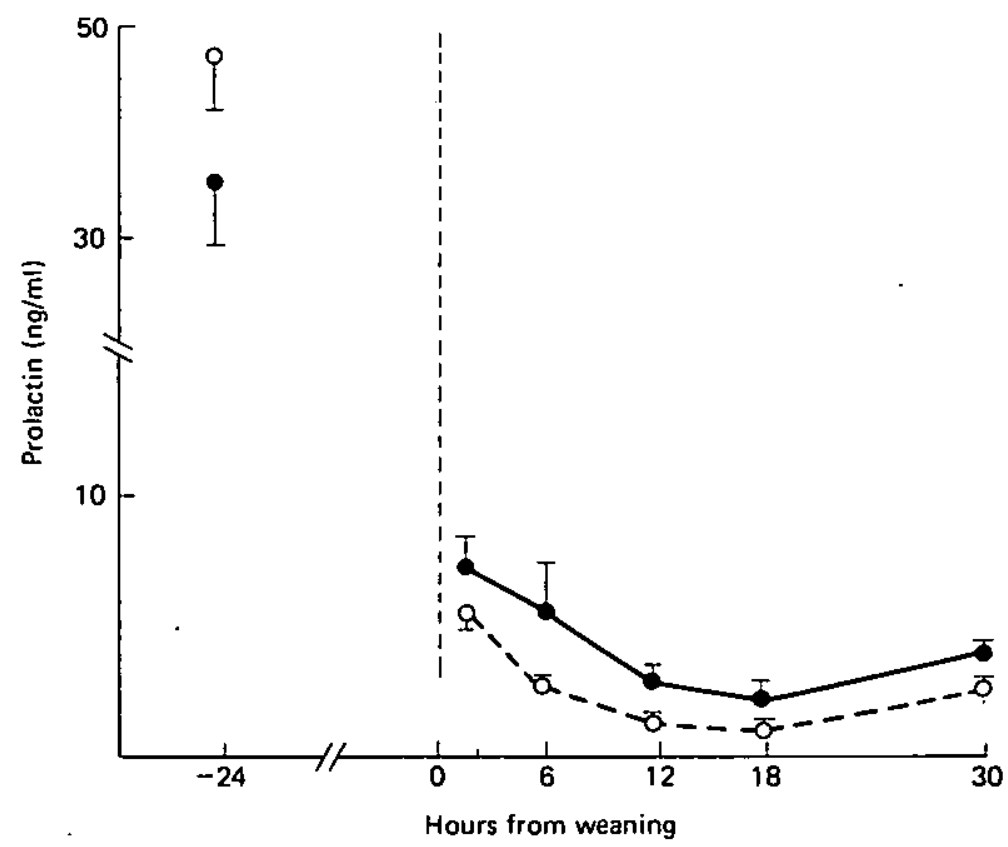

Figure 21.3 Serum prolactin concentrations in sows weaned 29-36 days post-partum. Note that a precipitous decline in prolactin concentrations occurs reaching basal values within 12 hours of weaning. By courtesy of Stevenson, Cox and Britt (1981)

gonadotrophic hormones has been demonstrated in the human female in that it disturbs the normal steroid secreting capacity of Graafian follicles cultured in vitro (McNatty, Sawers and McNeilly, 1974) and also prevents any increase in steroid output in response to endogenous or exogenous gonadotrophins in vivo (Seddon, 1970; Zarate et al., 1972; Reyes, Winter and Faiman, 1972; Rolland et al., 1975). In addition, evidence has accumulated in recent years for a dysfunction in the hypothalamic response to a positive oestrogen feedback signal, i.e. the induction of a preovulatory LH surge is blocked in hyperprolactinaemic women (Glass et al., 1975; 1976), sheep (Kann, Martinet and Schirar, 1976) and cattle (Radford, Nancarrow and Mattner, 1976; 1978) and a similar mechanism appears to be present in the lactating sow (Elsaesser and Parvizi, 1980) particularly during early lactation. The anti-gonadotrophic effects of prolactin have not been tested directly in the lactating sow but attempts to induce ovulation 
with gonadotrophin preparations such as pregnant mare's serum gonadotrophin (PMSG), human chorionic gonadotrophin (HCG) and gonadotrophin releasing hormone (GnRH) have had limited success before 21 days post-partum (Cole and Hughes, 1946; Heitman and Cole, 1956; Guthrie, Pursel and Frobish, 1978) indicating a block on the responsiveness of the ovary to gonadotrophic stimulation; this may, in part, be induced by the elevated plasma levels of prolactin.

In summary the endocrine events which control lactational anoestrus in the sow are still poorly understood but available data suggests that a combination of factors results in anovulation post-partum. The elevated levels of prolactin seen during lactation and maintained by suckling, may play a multifactorial role in that they may block both the effects of normal or elevated FSH secretions whilst also preventing positive oestrogen feedback where follicular development and oestrogen synthesis are present. Suckling, possibly by a direct neural suppression of $\mathrm{LH}$ releasing hormone secretion, also appears to depress LH, but not FSH, secretion and may therefore disturb the delicate $\mathrm{FSH} / \mathrm{LH}$ balance which is required for sustained follicular growth and development. Whilst other exteroceptive stimuli associated with piglet presence, e.g. sight, sound and smell, may have a complementary role to play in the maintenance of ovarian inactivity during lactation, this role would appear to be less important than that exerted by suckling.

\section{The endocrinology of the sow at weaning}

The total removal of the sow from her litter at weaning after 3-5 weeks of lactation normally results in an acceleration of follicular growth culminating in overt oestrus and ovulation within 4-8 days. It is the aim of this section to elucidate the factor(s) responsible for triggering and maintaining such follicular activity.

Pituitary levels of FSH change little in the immediate post-weaning period (Crighton and Lamming, 1969) and an examination of plasma FSH has indicated a similar pattern when sows are weaned after either three or five weeks of lactation, as shown in Figure 21.4 (Edwards, 1980).

In contrast pituitary LH levels rise significantly at weaning (Crighton and Lamming, 1969) indicating that weaning may functionally re-establish the synthesis and secretion of LH. Although daily measurements have indicated that plasma LH remains generally low at weaning (Aherne et al., 1976; Parvizi et al., 1976), very recent information has shown that a transient increase in basal LH secretion occurs at weaning and lasts 1-2 days as illustrated in Figure 21.5 (van de Wiel et al., 1979; Edwards, 1980). Furthermore this increase in LH secretion is associated with similar increases in hypothalamic GnRH content (Cox and Britt, 1981) within 60 hours of weaning, thereby increasing the potential for LH synthesis by the pituitary in preparation for the sustained LH secretion which occurs at oestrus.

Hence the increase in $\mathrm{LH}$ concentrations, coupled with normal or elevated FSH and decreased prolactin secretion, may represent the combination of factors (or trigger) required to stimulate follicular growth after weaning. The relative importance of each of these factors, and particularly their relationship to the stimuli generated by the piglets, has 


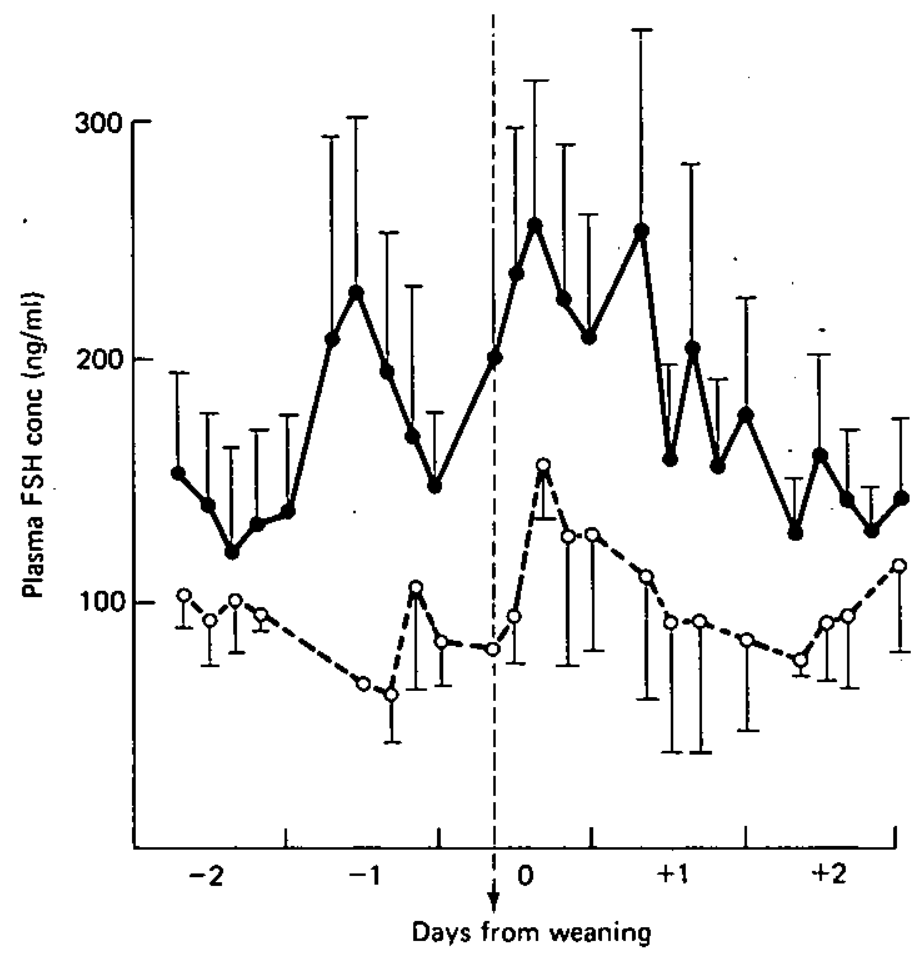

Figure 21.4 Mean plasma FSH concentrations for 3-week $\left(\mathrm{O}_{-}-\mathrm{O}\right)$ and 5-week (-_) weaned sows. The vertical dotted line indicates weaning. From Edwards (1980)

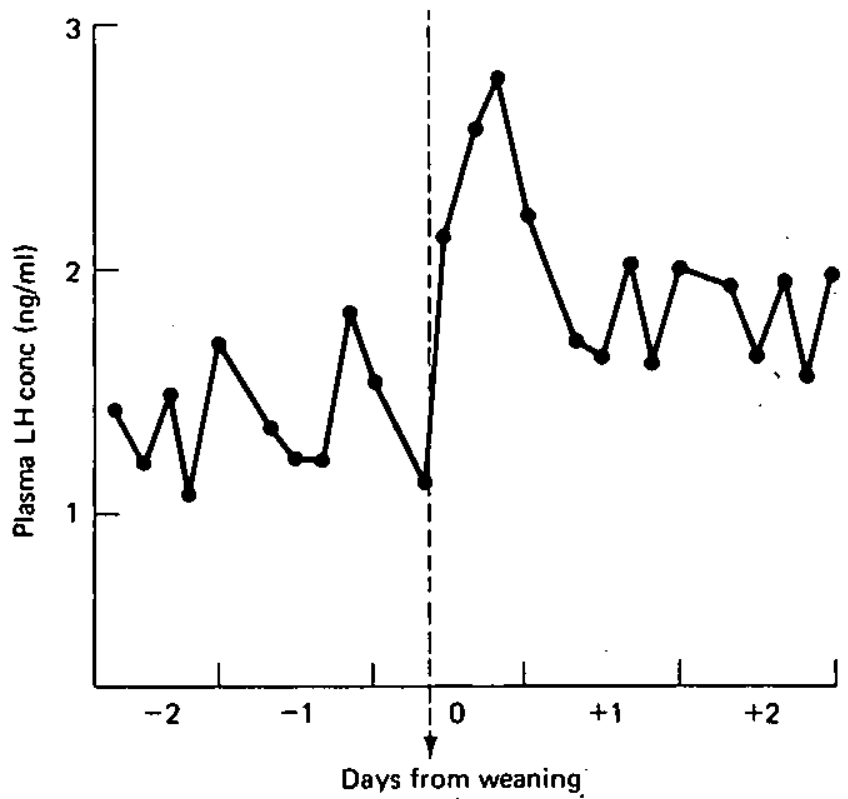

$I=$ S.E.M. .

Figure 21.5 Overall mean plasma LH concentrations for 3-week and 5-week weaned sows synchronized to 08.00 hours on the day of weaning as indicated by the vertical dotted line. From Edwards (1980) 
not yet been determined. However, Booman and van de Wiel (1980) have provided some useful information in this regard. This elegant series of experiments has indicated that:

(a) Separation of the sow and her litter for periods of four hours or more results in a rapid decline in plasma prolactin levels associated with an increase in basal LH secretion.

(b) Administration of exogenous prolactin does not completely prevent the increase in LH levels caused by removal of the piglets; however the rise in LH concentration is significantly reduced in sows infused with prolactin compared with those which are not.

(c) The suckling stimulus is the most potent stimulus generated by the piglets, when compared with sight, sound and smell, for increasing plasma prolactin and inhibiting LH secretion.

The consequences of the sustained follicular growth occurring after weaning will be considered in the following section.

\section{Endocrine changes at the post-weaning oestrus}

The endocrine changes associated with the post-weaning oestrus are basically similar to those seen in the oestrous cycle, but some interesting and potentially significant differences are apparent which appear to be associated with the length of the preceding lactation.

Two to six days after removal of the sow from her litter plasma oestrogens begin to rise and remain elevated for 2-3 days prior to, and partially including, oestrus (Ash and Heap, 1975; Aherne et al., 1976; van de Wiel et al., 1979; Edwards, 1980), as illustrated in Figure 21.6. Peak levels of oestrogen comparable to, or marginally lower than, those seen during the oestrous cycle are observed and the data also suggest that neither the length of lactation (Edwards, 1980) nor the interval from weaning to oestrus (Ash and Heap, 1975; van de Wiel et al., 1979) has any effect on the peak levels of oestrogen attained in sows weaned after lactations ranging from 2-6 weeks, although the numbers of animals are of necessity small in such experiments.

Oestrogen secretion is rapidly terminated by the pre-ovulatory surge of LH which occurs at oestrus (Aherne et al., 1976; Edwards, 1980; see Figure 21.6), an observation which is consistent with the reported ability of LH to terminate oestrogen secretion by cultured sheep Graafian follicles in vitro (Moor, 1974) and which also correlates well with observations from cyclic sows (see Chapter 8).

The characterization of this pre-ovulatory surge of LH has recently formed part of a detailed study of the reproductive physiology of the post-partum sow (Edwards, 1980). Since the pre-ovulatory surge of LH is directly responsible for ovulation, any changes in its characteristics, particularly in relation to the length of lactation, could have a major influence on the post-weaning reproductive performance of sows. A comparison of the amounts of circulating $\mathrm{LH}$ during the pre-ovulatory surge in 3-week or 5-week weaned sows is shown in Figure 21.7. A significant 


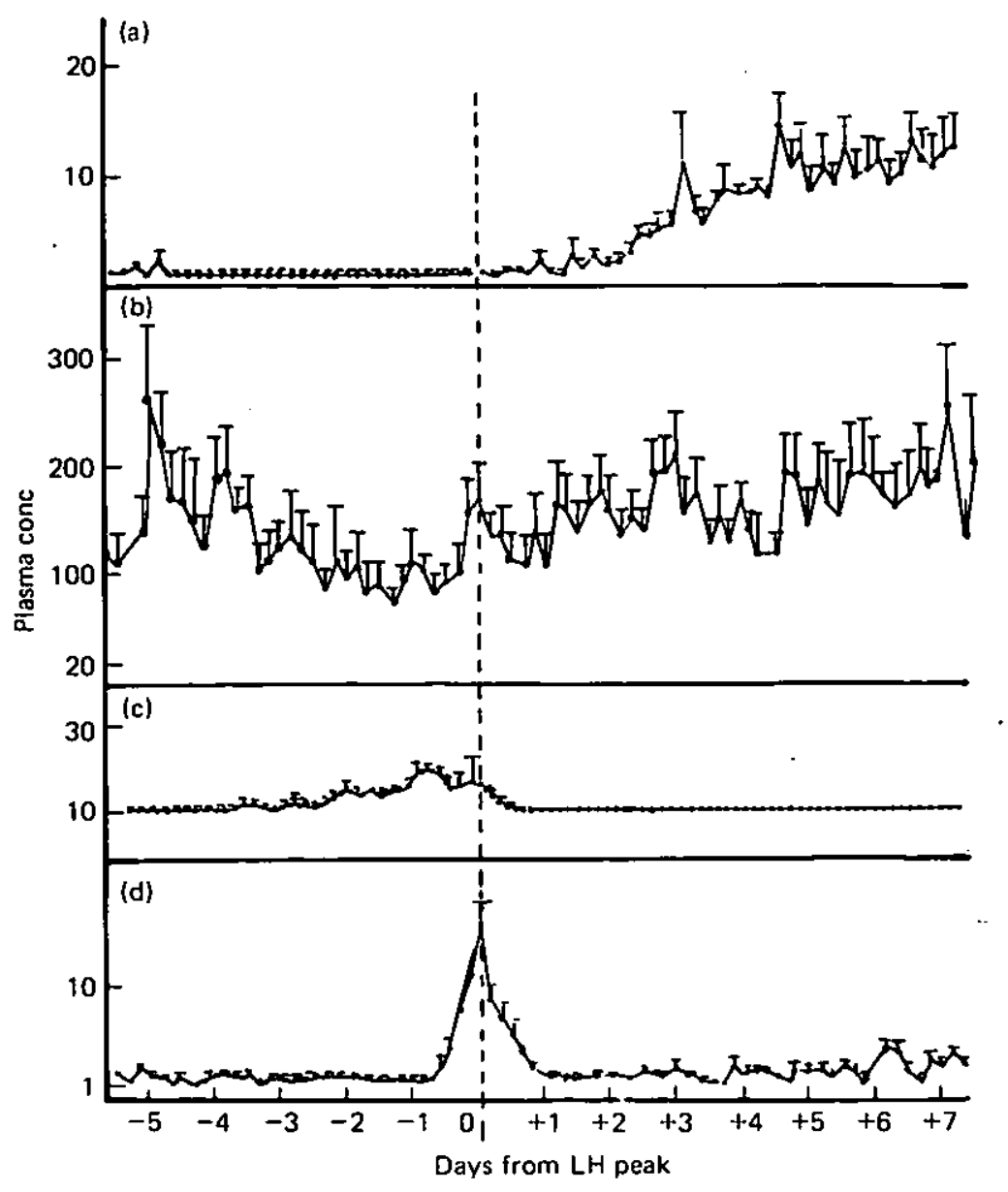

Figure 21.6 Mean plasma concentrations of (a) progesterone $(\mathrm{ng} / \mathrm{ml}),(\mathrm{b}) \mathrm{FSH}(\mathrm{ng} / \mathrm{ml})(\mathrm{c})$ oestradiol-17\% $(\mathrm{pg} / \mathrm{mt})$ and (d) LH $(\mathrm{ng} / \mathrm{ml})$ normalized around the first pre-ovulatory LH surge after weaning. From Edwards (1980)

depression in terms of mean peak height and total LH secreted (area under the curve) is seen after a 3-week compared with a 5-week lactation (or to cyclic sows at oestrus). Although the physiological basis for this difference is not clear a decrease in the responsiveness to GnRH induced by prolonged progesterone secretion during pregnancy and carried over into the post-partum period, may be inferred from studies in other species (Jequier, Vanthuyne and Jacobs, 1973; Jenkin and Heap, 1974; Webb et al., 1977). A similar recovery of the LH response to the positive feedback of oestradiol benzoate during lactation has recently been demonstrated in the pig (Elsaesser and Parvizi, 1980) and lends further support to the idea that the post-partum interval per se and not a reduction in the intensity of the suckling stimulus in late lactation, is responsible for the increased LH levels seen during the pre-ovulatory surges of 5-week weaned sows. The importance of these observations is obvious when 


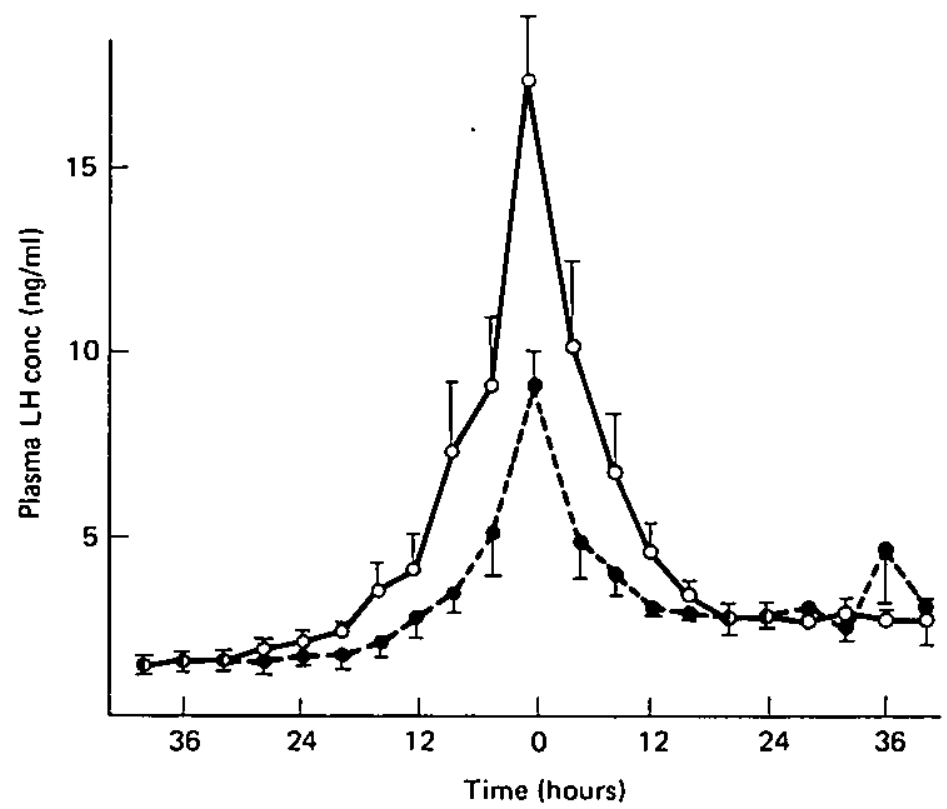

Figure 21.7 Mean plasma LH concentrations for 3-week weaned sows during the first pre-ovulatory LH surge after weaning. Time 0 represents the peak LH value observed. From Edwards (1980)

considering the lowered fecundity often associated with shorter lactations; reproductive performance may be seriously affected by early weaning, particularly in herds where reproductive problems are endemic.

Since LH secretion is so significantly affected during this critical phase of the sow's breeding cycle it is pertinent to examine the changes occurring in the secretion of the second pituitary gonadotrophin, FSH. A decline in pituitary FSH levels, in concert with LH levels, at the post-weaning oestrus has been considered representative of hormone release and the trigger for follicular growth and ovulation (Crighton and Lamming, 1969). The idea of elevated FSH secretion accompanying follicular growth (and oestrogen secretion) has in recent years been modified by an analysis of the plasma concentrations of this hormone during both the follicular phase of the oestrous cycle (Wilfinger, 1974; Foxcroft and Edwards, unpublished observations) and that preceding the post-weaning oestrus (Aherne et al., 1976; Edwards, 1980; Stevenson, Cox and Britt, 1981). FSH secretion is, in fact, at its lowest at the time of sustained follicular growth and maturation, when compared with either the luteal phase of the oestrous cycle, lactation or the first few days after weaning. Oestrogen is therefore capable of chronically inhibiting the secretion of FSH at a time when such a stimulus would appear to be most required and a detailed study of the receptor populations associated with follicular development in the pig is required before this anomalous situation can be resolved.

The determination of FSH levels in the plasma of cyclic sows has shown that approximately $50-60 \%$ of animals show a concomitant surge of LH 
and FSH (Wilfinger, 1974; Foxcroft and Edwards, unpublished observations) at oestrus. Of the studies in the weaned sow, one (Aherne et al., 1976) has indicated the presence of a slight increase in FSH concentrations on the day of oestrus (when sampling ceased) following a 3-week lactation whereas a second, more detailed, study (Edwards, 1980) has indicated an effect of lactation length on the occurrence of synchronous LH/FSH surges at oestrus after weaning at 3-weeks or 5-weeks of lactation. Of sows weaned at five weeks post-partum $75 \%$ produced distinct, coincident surges of FSH and LH whilst none of the sows weaned after three weeks of lactation showed such a rise, indicating that the hypothalamic-pituitary response after a longer lactation more closely resembles that seen in the cyclic sow at oestrus in terms of both the characteristics and quantity of FSH and LH released; such decreases may not be of critical importance to the induction of ovulation or the continuance of cyclic activity however, since $40-50 \%$ of cyclic sows continue to ovulate and cycle in similar circumstances. However, the combination of significantly depressed LH secretion, coupled with lowered tonic secretion of FSH at weaning and during the pre-follicular secretion of oestrogen and the absence of an FSH surge during oestrus, indicates that the earlier weaning of sows results in a general lowering of gonadotrophin secretion (and potential ovarian stimulation) at a time when such stimulation is most needed. This supports the earlier suggestion that reduced gonadotrophic stimulation may be the cause of lowered fertility and ultimately lowered productivity often associated with severely shortened lactations.

The role of prolactin at ovulation is an obscure one, if indeed it exists. A period of elevated prolactin secretion occurs at or around oestrus in cyclic sows (Wilfinger, 1974; van Landeghem and van de Wiel, 1977), but information from weaned sows is limited and contradictory. Several authors (Bevers, Willemse and Kruip, 1978; van Landeghem and van de Wiel, 1978; Stevenson, Cox and Britt, 1981) have shown a rise in prolactin at oestrus, but Edwards (1980) failed to identify such a rise in weaned sows. Since the role of prolactin in ovulation is unclear, it is not surprising to find that blockade of prolactin secretion at this time does not interfere with the ovulation process (Niswender, 1972) and it has been suggested that the oestrogen trigger responsible for the initiation of the LH surge also initiates the rise in prolactin associated with oestrus in the pig (Bevers et al., 1978; Stevenson, Cox and Britt, 1981) and other species (Chen and Meites, 1970; Schams, 1974).

What may be of greater importance to the continuance of reproductive cycles is the sustained secretion of FSH, in the absence of significant LH secretion, seen around the time of ovulation approximately $24-48$ hours after the pre-ovulatory LH/FSH surge (Edwards, 1980; Stevenson, Cox and Britt, 1981). This phase of secretion is consistently observed in cyclic sows (Wilfinger, 1974; Foxcroft and Edwards, unpublished observations) and its characteristics are similar in sows weaned at 3 or 5 weeks of lactation, in contrast to the differences observed during the pre-ovulatory gonadotrophin surge. Although this phase of secretion is observed in cyclic and weaned sows after oestrus its physiological significance remains unclear. It would appear that normal negative feedback responses to exogenous oestrogen occur at this time, i.e. FSH secretion can be 
suppressed, but in such situations ovulation is not adversely affected (Edwards, 1980). The cumulative effects of such treatment, however, on subsequent follicular growth and ovulation are unknown; repeated treatment may decrease ovulation rate and/or follicular function and result in lowered fertility and/or anoestrus.

Following oestrus and ovulation progesterone levels rise sharply and enter a phase of secretion which is indistinguishable from the luteal phase of a normal oestrous cycle (Ash and Heap, 1975; Baldwin and Stabenfeldt, 1975; Parvizi et al., 1976; Stevenson, Cox and Britt, 1981). There is no apparent effect of lactation length on the pattern or peak levels of progesterone secretion attained (Edwards, 1980) even when the litter is removed at birth (Ash and Heap, 1975) as shown in Figure 21.8. The

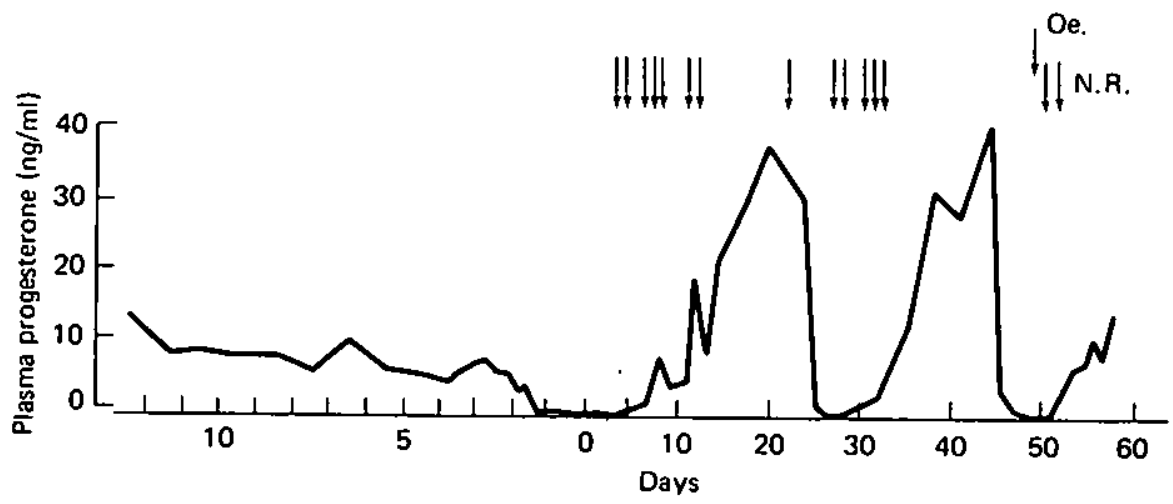

Figure 21.8 Early weaning and the plasma concentrations of progesterone. Parturition occurred on day 0 , and the piglets were separated from the sow immediately after delivery. Oe (top arrow), oestrus and fertile mating: N.R. (lower arrows), non-receptive when tested with the boar. From Ash and Heap (1975)

significance of some small amounts of progesterone secreted in a minority of sows prior to the LH surge is not apparent. Since these fluctuations occurred at the time of elevated oestrogen secretion they may only reflect a metabolic by-product of such secretion (Edwards, 1980). However, no evidence for this type of secretion has been seen in the follicular phase of the normal oestrous cycle (Foxcroft and Edwards, unpublished observations).

A proportion of sows, however, fail to show oestrus and ovulation within 10-12 days of weaning and this failure of reproductive activity is associated with a lack of oestrogen production (Aherne et al., 1976; van de Wiel et al., 1979; Edwards, 1980) indicating a lack of ovarian responsiveness to gonadotrophin stimulation. Although the endocrine function in such sows is poorly understood due to a lack of basic data, it would appear that FSH levels are low initially and may rise within 1-3 days of weaning (Aherne $e t$ al., 1976), or are normal and become elevated 3-6 days after weaning. This normal or elevated secretion of FSH may continue for at least two weeks post-weaning if oestrus is not stimulated. Basal LH levels appear to rise at weaning (Edwards, 1980) but, in contrast to sows returning to oestrus within 4-6 days, remain elevated or increase for 6-8 days after weaning. A 
period of depressed LH secretion may then ensue, associated with the secretion of oestrogen; conversely basal LH levels may remain elevated for periods in excess of 2-3 weeks post-weaning if oestrogen secretion is not stimulated. Similar changes in the pattern of gonadotrophin secretion have been observed in sows ovariectomized whilst lactating (Stevenson, Cox and Britt, 1981). In such sows oestrogen replacement 8-10 days postweaning results in normal feedback responses and a pre-ovulatory LH surge on day 11 , indicating that the protracted weaning to oestrus interval seen in some sows is the result of a lack of an adequate ovarian response and not due to a malfunction of the hypothalamus or pituitary. The factors controlling the ovarian response to gonadotrophins post-weaning are unclear at present but do not appear to include a carryover of the hypersecretion of prolactin from lactation into the post-weaning period (van de Wiel et al., 1979; Edwards, 1980). Elegant studies in the rat indicate that the ovarian response to gonadotrophic stimulation is intimately concerned with the proper, sequential development of follicular gonadotrophin receptors (Richards, Rao and Ireland, 1978). Similar studies of the follicular receptor populations on the ovaries of lactating and weaned sows are needed to enable a clearer understanding of the factors limiting ovarian development both during lactation and after weaning.

\section{Episodic LH secretion and ovarian function}

Great emphasis in recent years has been placed on the pulsatile or episodic nature of LH secretion in the control of gonadal function in several species, e.g. sheep (Karsch et al., 1978) and humans (Souvatzoglou et al., 1973). The ability of gonadal steroids and in particular, oestrogen, to modulate this pulsatile LH secretion has been reported in pigs (Foxcroft, Pomerantz and Nalbandov, 1975) and Rhesus monkeys (Knobil, 1974) amongst others. Progesterone is thought to play a pivotal role in the control of the sheep oestrous cycle (Hauger, Karsch and Foster, 1977) by its modification of tonic or pulsatile LH secretion and similar changes in pulsatile LH patterns have been observed in the luteal phase of the sow oestrous cycle (Foxcroft and Edwards, unpublished observations). Whether these characteristic changes in pulsatile LH secretion are intimately concerned with ovarian function or simply reflect the changing patterns of steroids during the oestrous cycle has not yet been determined for the pig. Since lactation is associated with a block on sustained follicular development, and the period immediately after weaning represents a transitional phase in ovarian development, it would be useful to know if this transition is associated with any characteristic changes in pulsatile gonadotrophin output. Evidence has already been presented for a weaning-associated rise in basal LH secretion which resembles that seen in the follicular phase of the sheep oestrous cycle. Studies in Nottingham (Edwards, 1980) in the lactating and weaned sow have indicated that (see Figures 21.9 and 21.10):

(a) the length of lactation has no consistent effect on the characteristics of pulsatile LH secretion; 


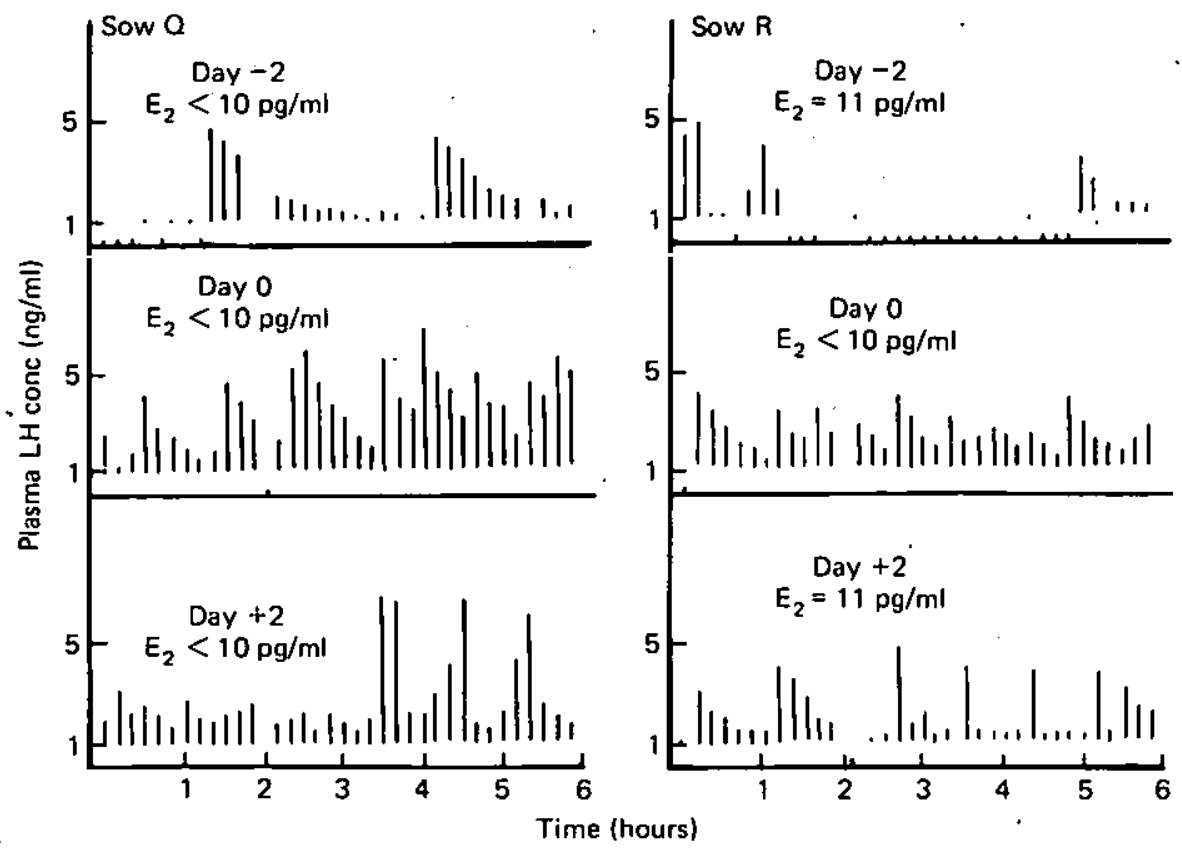

Figure 21.9 Episodic or pulsatile L.H secretion around weaning for two sows weaned after 3 weeks of lactation. Weaning occurred on day 0 and plasma progesterone concentrations were basal at all times. $E_{2}=$ oestradiol concentration. Note the rise in LH baseline secretion at day 0 in the absence of any consistent effect on the characteristics of pulsatile secretion. From Edwards (1980)

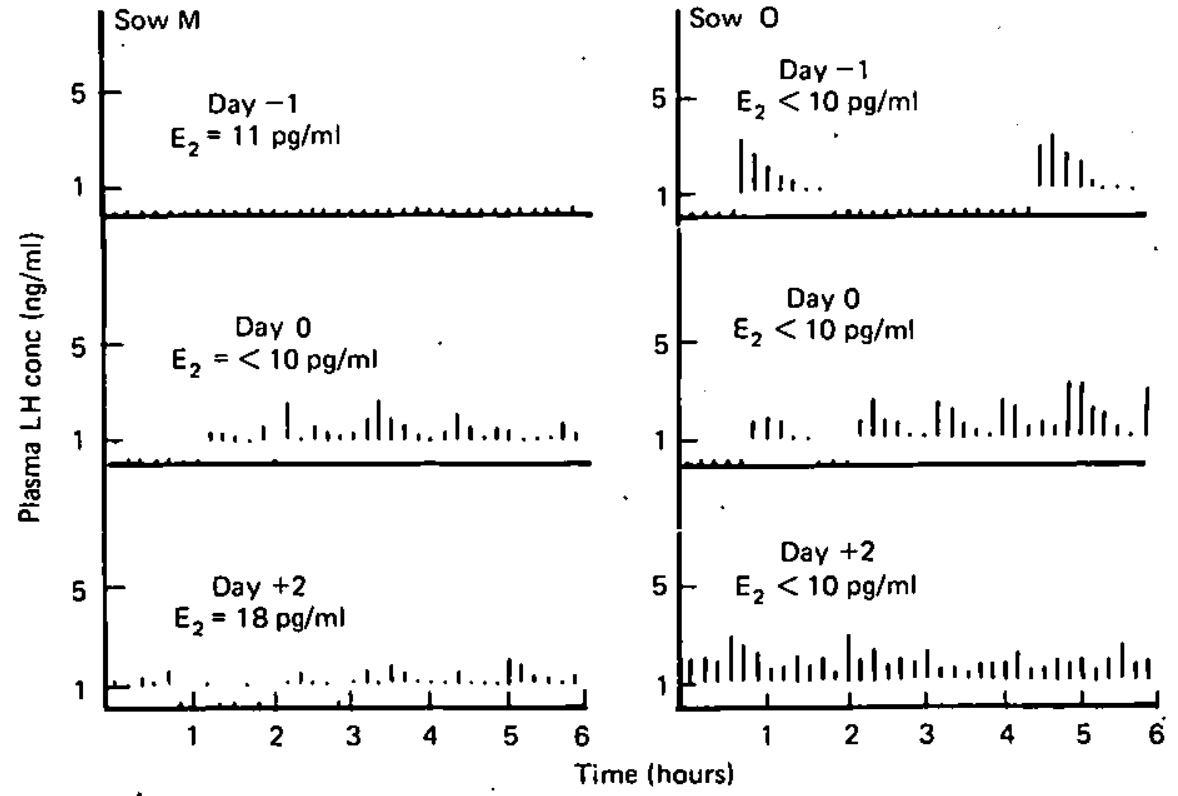

Figure 21.10 Episodic or pulsatile LH secretion around weaning for two sows weaned after 5 weeks of lactation. Weaning occurred on day 0 and plasma progesterone concentrations were basal at all times. $E_{2}=$ oestradiol concentration. Again a rise in basal $\mathrm{LH}$ secretion occurs at day 0 in the absence of any consistent effect on the characteristics of pulsatile LH secretion. From Edwards (1980) 
(b) weaning is not associated with characteristic changes in this pulsatile pattern, although basal LH secretion is elevated;

(c) patterns of pulsatile LH secretion only become ordered during the pre-ovulatory secretion of oestradiol, when they resemble the changes seen in the follicular phase of the oestrous cycle.

Subsequent to the pre-ovulatory LH surge, pulsatile secretion is similar in all respects to that seen in the oestrous cycle (Figure 21.11). Since it is not possible to demonstrate a characteristic change in pulsatile $\mathrm{LH}$ secretion in relation to weaning, the function of such a mode of secretion

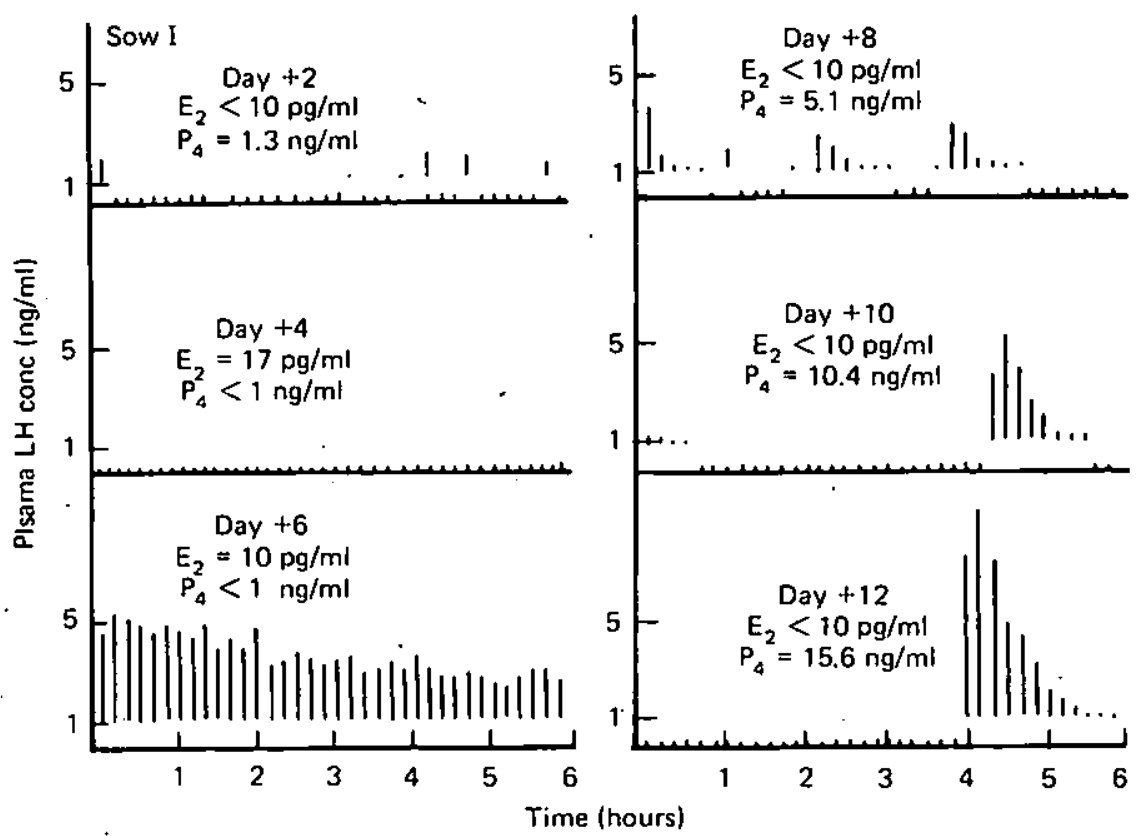

Figure 21.11 Episodic LH secretion in a sow from 2-12 days after weaning at 5 weeks post-partum. $E_{2}=$ oestradiol, $P_{4}=$ progesterone concentrations. The pre-ovulatory surge of LH occurred on days $5-6$. Similar changes in pulsatile LH secretion occurred in sows weaned after 3 weeks of lactation (data not shown). From Edwards (1980)

remains unclear and may simply reflect a pulsatile release of GnRH from the hypothalamus. Until further research is undertaken the problem will remain the subject of much speculation.

\section{Conclusions}

As regards the overall control of reproductive function during lactation it appears that the hypothalamic-pituitary unit, primarily under the influence of the suckling stimulus, is responsible for the limited follicular development, anoestrus and anovulation which normally prevails. Although our knowledge of the endocrine events which accompany these morphological and behavioural changes has increased dramatically over the last five years, 
much more detailed information is required before a complete understanding can be had of the intricate endocrine relationships involved in the control of post-partum reproduction in the pig. In particular the changes occurring at the ovarian level in terms of follicular gonadotrophin receptors need to be elucidated and studied in relation to the endocrine events now known to occur as lactation progresses and the sow is weaned. The influence of lactation length on such phenomena is also an area which requires much greater research effort.

Whether or not it will ever be possible, or even desirable, to stimulate reproduction during lactation is debatable but a more controlled system of sow breeding must be the ultimate aim of current work, using either managemental changes and/or hormone treatment to produce the optimal number of live piglets when required.

It remains to be determined just how quickly such a system can be made practical and attractive to the producer.

\section{References}

AHERNE, F.X., CHRISTOPHERSON, R.J., THOMPSON, J.R. and HARDIN, R.T. (1976). Factors affecting the onset of puberty, post weaning oestrus and blood hormone levels of Lacombe gilts. Can. J. Anim. Sci. 56, 681-692 ASH, R.W. and HEAP, R.B. (1975). Oestrogen, progesterone and corticosteroid concentrations in peripheral plasma of sows during pregnancy, parturition, lactation and after weaning. J. Endocr. 64, 141-154

ASH, R.W., BANKS, P., BROAD, S. and HEAP, R.B. (1972). Techniques for studying changes in some peripheral blood components and steroid hormones in pregnant and lactating sows. J. Physiol. (Lond.) 224, $40 \mathrm{P}-41 \mathrm{P}$

ASH, R.W., BANKS, P., BAILES, G., BROAD, S. and HEAP, R.B. (1973). Plasma oestrogen, progesterone and cortisosteroid concentrations in the pregnant, parturient and lactating sow. J. Reprod. Fert. 33, 359-360

BAKER, L.N., WOEHLING, H.L., CASIDA, L.E. and GRUMMER, R.H. (1953). Occurrence of oestrus in sows following parturition. J. Anim. Sci. 12, 33-38

BALDWIN, D.M. and STABENFELDT, G.H. (1975). Endocrine changes in the pig during late pregnancy, parturition and lactation. Biol. Reprod. 12, 508-515

BEVERS, M.M., WILLEMSE, A.H. and KRUIP, Th.A.M. (1978). Plasma prolactin levels in the sow during lactation and the postweaning period as measured by radioimmunoassay. Biol. Reprod. 19, 628-634

BOOMAN, P. and VAN DE WIEL, D.F.M. (1980). Lactational anoestrus in the pig: possible relationship with hyperprolactinaemia. Report B-157. Instituut voor Veeteeltkundig Onderzoek "Schoonoord", Driebergseweg 10, Zeist, Holland

BURGER, J.F. (1952). Sex physiology of pigs. Onderstepoort J. vet. Res. Suppl. 2, 3-218

CAMPBELL, C.J. and SCHWARTZ, N.B. (1979). Time course of serum FSH suppression in ovariectomized rats injected with porcine follicular fluid 
(folliculostatin): Effect of oestradiol treatment. Biol. Reprod. 20, 10931098

CHEN, C.L. and MEITES, J. (1970). Effects of oestrogen and progesterone on serum and pituitary prolactin levels in ovariectomized rats. Endocrinology 86, 503-506

COLE, H.H. and HUGHES, E.H. (1946). Induction of oestrus in lactating sows with equine gonadotrophin. J. Anim. Sci. 5, 25-29

COX, N.M. and BRITT, J.H. (1981). Relationship between endogenous GnRH and post-weaning endocrine events in sows (Abstract). Annual Meeting of the Southern Section, American Society of Animal Science, Atlanta, Georgia

CRIGHTON, 'D.B. (1967). Effects of lactation on the pituitary gonadotrophins of the sow. In Reproduction in the Female Mammal (G.E. Lamming and E.C. Amoroso, Eds.), pp. 223-238. London, Butterworths

CRIGHTON, D.B. and LAMMING, G.E. (1969). The lactational anoestrus of the sow; the status of the anterior pituitary-ovarian system during lactation and after weaning. $J$. Endocr. 43, 507-519

EDQVIST, L.E., EINARSSON, S. and SETTERGREN, I. (1974). Ovarian activity and peripheral plasma levels of oestrogens and progesterone in the lactating sow. Theriogenology 1, 43-49

EDWARDS, S. (1980). Reproductive physiology of the post-parturient sow. PhD Thesis. University of Nottingham

ELSAESSER, F. and PARVIZI, N. (1980). Partial recovery of the stimulatory oestrogen feedback action on $\mathrm{LH}$ release during late lactation in the pig. J. Reprod. Fert. 59, 63-67

FOXCROFT, G.R., POMERANTZ, D.K. and NALBANDOV, A.V. (1975). Effects of oestroadiol-17- $\beta$ on LHRH/FSHRH induced and spontaneous LH release in pre-pubertal female pigs. Endocrinology 96, 551-557

GLASS, M.R., SHAW, R.W., BUTT, W.R., EDWARDS, R.L. and LONDON, D.R. (1975). An abnormality of oestrogen feedback in amenorrhea-galactorrhea. Br. med. J. 3, 274-275

GLASS, M.R., SHAW, R.W., EDWARDS, R.L., BUTT, W.R., WILLIAMS, J. and LONDON, D.R. (1976). Modulation of gonadotrophin release by steroid hormones in women with hyperprolactinaemia. J. Endocr. 69, 46P-47P

GUTHRIE, H.D., PURSEL, V.G. and FROBISH, L.T. (1978). Attempts to induce conception in lactating sows. J. Anim. Sci. 47, 1145-1151

HAUGER, R.L., KARSCH, F.J. and FOSTER, D.L. (1977). A new concept for control of the oestrous cycle of the ewe based on the temporal relationships between $\mathrm{LH}$, oestradiol and progesterone in peripheral serum and evidence that progesterone inhibits tonic LH secretion. Endocrinology 101, 807-817

HEITMAN, H. and COLE, H.H. (1956). Further studies in the induction of oestrus in lactating sows with equine gonadotrophin. J. Anim. Sci. 15, 970-977

HOLNESS, D.H. and HUNTER, R.H.F. (1975), Post-partum oestrus in the sow in relation to the concentration of plasma oestrogens. J. Reprod. Fert. 45, $15-20$

JENKIN, G. and HEAP, R.B. (1974). The lack of response of the sheep pituitary to LHRH stimulation in gestation and early lactation; the probable role of progesterone. J. Endocr. 61, XII 
JEQUIER, A.M., VANTHUYNE, C. and JACOBS, H.S. (1973). Gonadotrophin secretion in lactating women: response to LHRH/FSHRH in the puerperium. J. Endocr. 59, XIV

KANN, G., MARTINET, J. and SCHIRAR, A. (1976). Impairment of luteinizing hormone release following oestrogen administration to hyperprolactinaemic ewes. Nature, Lond. 264, 465-466

KARSCH, F.J., LEGAN, S.J., RYAN, K.D. and FOSTER, D.L. (1978). The feedback effects of ovarian steroids on gonadotrophin secretion. In Control of Ovulation, (D.B. Crighton, N.B. Haynes, G.R. Foxcroft and G.E. Lamming, Eds.), pp. 29-43. London, Butterworths

KNOBIL, E. (1974). On the control of gonadotrophin secretion in the Rhesus monkey. Recent Prog. Horm. Res. 30, 1-36

LAMMING, G.E. (1978). Reproduction during lactation. In Control of Ovulation, (D.B. Crighton, N.B. Haynes, G.R. Foxcroft and G.E. Lamming, Eds.), pp. 335-353. London, Butterworths

LAUDERDALE, J.W., KIRKPATRICK, R.L., FIRST, N.L., HAUSER, E.R. and CASIDA, L.E. (1965). Ovarian and pituitary gland changes in periparturient sows. J. Anim. Sci. 24, 1100-1103

McNATTY, K.P., SAWERS, R.S. and McNEILLY, A.S. (1974). A possible role for prolactin in control of steroid secretion by the human Graafian follicle. Nature, Lond. 250, 653-655

MELAMPY, R.M., HENRICKS, D.M., ANDERSON, L.L., CHEN, C.L. and SCHULTZ, J.R. (1966). Pituitary FSH and LH concentrations in pregnant and lactating pigs. Endocrinology 78, 801-804

MINAGUCHI, H. and MEITES, J. (1967). Effects of suckling on hypothalamic LH-releasing factor and prolactin inhibiting factor and on pituitary LH and prolactin. Endocrinology 80, 603-607

MOOR, R.M. (1974). The ovarian follicle of the sheep: inhibition of oestrogen secretion by luteinizing hormone. J. Endocr. 61, 455-463

NISWENDER, G.D. (1972). The effect of ergocornine on reproduction in sheep. Biol. Reprod. 7, 138-139

PALMER, W.M., TEAGUE, H.S. and VENZKE, W.G. (1965a). Macroscopic observations on the reproductive tract of the sow during lactation and early post-weaning. J. Anim. Sci. 24, 541-545

PALMER, W.M., TEAGUE, H.S. and VENZKE, W.G. (1965b). Histological changes in the reproductive tract of the sow during lactation and early post-weaning. J. Anim. Sci. 24, 1117-1125

PARVIZI, N., ElSAESSER, F., SMIDT, D. and ElLENDORFF, F. (1976). Plasma LH and progesterone in the adult female pig during the oestrous cycle, late pregnancy and lactation, and after ovariectomy and pentobarbitone treatment. J. Endocr. 69, 193-203

RADFORD, H.M., NANCARROW, C.D. and MATTNER, P.E. (1976). Evidence for hypothalamic dysfunction in suckled beef cows. Theriogenology 6, 641

RADFORD, H.M., NANCARROW, C.D. and MATTNER, P.E. (1978). Ovarian function in suckling and non-suckling beef cows post-partum. J. Reprod. Fert. 54, 49-56

RAESIDE, J.I. (1963). Urinary oestrogen excretion in the pig during pregnancy and parturition. $J$. Reprod. Fert. 6, 427-431

RAYFORD, P.L., BRINKLEY, H.J., YOUNG, E.P. and REICHERT, L.E. (1974). Radioimmunoassay of porcine FSH. J. Anim. Sci. 39, 348-354 
REYES, F.I., WINTER, J.S.D. and FAIMAN, C. (1972). Pituitary-ovarian interrelationships.during the puerperium.,Am. J. Obstet. Gynec. 114, 589-594

RICHARDS, J.S., RAO, M.C. and IRELAND, J.J. (1978). Actions of pituitary gonadotrophins on the ovary. In Control of Ovulation, (D.B. Crighton, N.B. Haynes, G.R. Foxcroft and G.E. Lamming, Eds.), pp. 197-216. London, Butterworths

ROBERTSON, H.A. and KING, C.J. (1974). Plasma concentrations of progesterone, oestrone, oestradiol-17- $\beta$ and oestrone sulphate in the pig at implantation, during pregnancy and at parturition. J. Reprod. Fert. 40, 133-141

ROLLAND, R., LEQUIN, R.M., SCHELLEKENS, L.A. and de JONG, F.H. (1975). The role of prolactin in the restoration of ovarian function during the early post-partum period in the human female. I. A study during physiological lactation. Clin. Endocr. 4, 15-25

SASSER, R.G., HEGGE, F.N., CHRISTIAN, R.E. and FAlK, D.E. (1973). Plasma oestrogens in pregnant gilts. J. Anim. Sci. 37, 327

SCHAMS, D. (1974). Untersuchungen uber Prolactin beim Rind. Hamburg and Berlin, Verlag Parey

SEDDON, R.J. (1970). The ovarian response in women to large single injections of human menopausal gonadotrophin and human chorionic gonadotrophin. J. Reprod. Fert. 23, 299-305

SELF, H.L. and GRUMMER, R.H. (1958). The rate and economy of pig gains and the reproductive behaviour in sows when litters are weaned at 10 days, 21 days or 56 days of age. J. Anim. Sci. 17, 862-868

SOUVATZOGLOU, A., METZGER, 1., KULLACK, W., BUTENANDT, $O$. and HENDERKOTT, V. (1973). The functional significance of episodic LH secretion. Acta endocr. Suppl. 173, Abstract 42

STEVENSON, J.S., COX, N.M. and BRITT, J.H. (1981). Role of the ovary in controlling LH, FSH and prolactin secretion during and after lactation in pigs. Biol. Reprod. 24, 341-353

STEVENSON, J.S. and BRITT, J.H. (1981). Luteinizing hormone, total oestrogens and progesterone secretion during lactation and after weaning in sows. Theriogenology 14, 453-462

VAN DE WIEL, D.F.M. VAN LANDEGHEM, A.A.J., WILLEMSE, A.H. and BEVERS, M.M. (1979). Endocrine control of ovarian function after weaning in the domestic sow. J. Endocr. 80, 69P

VAN LANDEGHEM, A.A.J. and VAN DE WIEL, D.F.M. (1977). Plasma prolactin levels in gilts during the oestrous cycle and at hourly intervals around the time of oestrus. Acta endocr. 85, Suppl. 212, Abstract 233

VAN LANDEGHEM, A.A.J. and VAN DE WIEL, D.F.M. (1978). Radioimmunoassay for porcine prolactin: plasma levels during lactation, suckling and weaning and after TRH administration. Acta endocr. 88, 653-667

WARNICK, A.C., CASIDA, L.E. and GRUMMER, R.H. (1950). The occurrence of oestrus and ovulation in post-partum sows. J. Anim. Sci. 9, 66-72

WEBB, R., LAMMING, G.E., HAYNES, N.B., HAFS, H.D. and MANNS, J.G. (1977). Response of cyclic and post-partum suckled cows to injections of synthetic LHRH. J. Reprod. Fert. 50, 203-210

WILFINGER, W.W. (1974). Plasma concentrations of LH, FSH and prolactin in ovariectomized, hysterectomized and intact swine. Diss. Abstr. 35, 2985-B. 
ZARATE, A., CANALES, E.S., SORIA, J., RUIZ, F. and MACGREGOR, C. (1972). Ovarian refractoriness during lactation in women: effect of gonadotrophin stimulation. Am. J. Obstet. Gynec. 114, 589-594 